\title{
Vitamin D and atypical femoral fractures
}

\author{
A. C. Ng・J. S.-B. Koh • T.-S. Howe
}

Received: 9 September 2012 / Accepted: 11 September 2012 / Published online: 6 December 2012

(C) International Osteoporosis Foundation and National Osteoporosis Foundation 2012

\section{Dear Editors,}

There have been recent reports of atypical femoral fractures occurring in patients treated with bisphosphonates [1]. While the primary hypothesis has centered on the oversuppression of bone turnover, there have been suggestions that vitamin D deficiency might also be an important risk factor $[1,2]$. Thus far, only one series has examined the association between vitamin D levels and atypical femoral fractures [2]. In the study by Girgis et al., serum 25-hydroxyvitamin $\mathrm{D}(25 \mathrm{OHD})$ of less than $16 \mathrm{ng} / \mathrm{mL}$ was associated with an increased the risk of atypical subtrochanteric fractures $(\mathrm{OR}=3.2)$. While it is plausible that vitamin $\mathrm{D}$ deficiency may play a role in the pathogenesis of these fractures since it is associated with impaired calcium absorption, compensatory hyperparathyroidism, and increased bone resorption, it was not an evident risk factor in our clinical experience. In our case series, which was one of the first published series describing this phenomenon [3], there were 16 women, age 52 to 91 years and of Asian ethnicity, who had a serum 25OHD level ascertained at the time of presentation between May 2004 and March 2010. They were compared to age-, ethnicity-, and sex-matched controls with low-energy osteoporotic femoral neck or pertrochanteric fractures admitted during the same period of time. Vitamin D deficiency was defined as $25 \mathrm{OHD}<20 \mathrm{ng} / \mathrm{mL}$. Baseline characteristics

\footnotetext{
A. C. $\operatorname{Ng}(\bowtie)$

Department of Endocrinology, Singapore General Hospital,

Singapore, Singapore

e-mail: drng@the-endo-clinic.com

J. S.-B. Koh • T.-S. Howe

Department of Orthopaedic Surgery, Singapore General Hospital,

Singapore, Singapore
}

were similar between cases and controls. The median $25 \mathrm{OHD}$ was $26.2 \mathrm{ng} / \mathrm{mL}$ in cases vs $19.0 \mathrm{ng} / \mathrm{mL}$ in controls $(p=0.0127)$, consistent with a greater use of calcium $(81.3$ vs $37.5 \%, p=0.004)$ and vitamin $\mathrm{D}(68.8$ vs $34.4 \%, p=$ $0.024)$ supplementation in cases vs. controls. Only 3 out of 16 cases $(18.75 \%)$ were vitamin D deficient, while 17 out of 32 controls $(53.13 \%)$ were vitamin D deficient ( $p=$ 0.031 ). The odds ratio for vitamin D deficiency in cases vs controls was 0.20 (95\% CI 0.03, 0.97). The main limitation of this analysis was the measurement of $25 \mathrm{OHD}$ at the time of presentation rather than at the initiation of and during bisphosphonate therapy. Nevertheless, our study indicated that vitamin D status was significantly better in cases vs controls at the time of fracture, suggesting that vitamin D status might be a less important factor than previously thought in the development of bisphosphonate-associated atypical femoral fractures.

\section{References}

1. Shane E, Burr D, Ebeling PR, Abrahamsen B, Adler RA, Brown TD, Cheung AM, Cosman F, Curtis JR, Dell R, Dempster D, Einhorn TA, Genant HK, Geusens P, Klaushofer K, Koval K, Lane JM, McKiernan F, McKinney R, Ng A, Nieves J, O'Keefe R, Papapoulos S, Sen HT, van der Meulen MC, Weinstein RS, Whyte M (2010) Atypical subtrochanteric and diaphyseal femoral fractures: report of a task force of the American Society for Bone and Mineral Research. J Bone Miner Res 25:2267-2294

2. Girgis CM, Sher D, Seibel MJ (2010) Atypical femoral fractures and bisphosphonate use. N Engl J Med 362:1848-1849

3. Goh SK, Yang KY, Koh JS, Wong MK, Chua SY, Chua DT, Howe TS (2007) Subtrochanteric insufficiency fractures in patients on alendronate therapy: a caution. J Bone Joint Surg Br 89:349-353 